\title{
ЗАРУБЕЖНЫЙ ОПЫТ ИНИЦИАТИВНОГО БЮДЖЕТИРОВАНИЯ В УПРАВЛЕНИИ ГОСУДАРСТВЕННЫМИ ФИНАНСАМИ
}

\author{
(c) 2018 Белостоцкий Алексей Александрович \\ кандидат экономических наук, доцент \\ Курский государственный университет \\ 305000, ул. Радищева, д. 33 \\ E-mail: a.a.belostotskiy@yandex.ru
}

В статье проанализированы зарубежный опыт практики инициативного бюджетирования, этапы из развития в мире, влияние иностранных механизмов на развитие инициативного бюджетирования в субъектах РФ, его финансовое обеспечение, а также исследован рейтинг регионов по реализации данных практик и проведения необходимых мероприятий для достижения определенного социально экономического уровня развития территорий.

Ключевые слова: зарубежный опыт, инициативное бюджетирование, этапы развития партисипаторного бюджетирования, федеральные целевые программы, социально-экономическое развитие территорий.

Инициативное бюджетирование - это отечественный вариант распространенного в мире партисипаторного бюджетирования (от англ. participate - участвовать), которое заключается в вовлечении граждан в бюджетный процесс, данное направление возникло в конце 80-х годов прошлого столетия в Бразилии. Возникновение данной практики было обусловлено тем, что возникла острая необходимость взаимодействия местного населения и государственных (муниципальных) структур. Появлению партисипаторного бюджетирования в современных условиях способствовало активная жизненная позиция населения, стремящихся благоустроить собственную территорию на фоне стремления органов власти более прозрачно и эффективно расходовать бюджетные ресурсы на социокультурные цели.

Партисипаторное бюджетирование - это сочетание практик по проблемам развития муниципальных образований на основе вовлечения инициативных граждан в решение бюджетного финансирования объектов социальной инфраструктуры на местном уровне и обеспечении контрольных функций в процессе реализации проектов.

Впервые возникновение данной практики партисипаторного бюджетирования стал один из крупнейших городов Бразилии Порту-Алегри, который является столицей южного бразильского штата Риу-Гранди-ду-Сул. В дальнейшем, именно это место будут считать началом развития практик партисипаторного бюджетирова- ния по всему миру. Пионером данного движения столица бразильского штата стала в связи с тем, что левая часть местной исполнительной власти проявила политическую волю и взяла на себя ответственность по бюджетному финансированию социальных объектов, представляющих интерес для местного населения, которое давно стремилось к взаимодействию с местными органами власти.

Социально-экономические проблемы, которые существовали в исследуемый период крупных бразильских городах крайне нуждались в реформировании, финансировании из бюджетных источников и, собственно в обнаружении этих самых источников, так, например, 1/3 населения Порту-Алегри имела ветхое жильё, нуждалось в питьевой воде и не имела доступа к учреждениям образования и здравоохранения. Именно тогда, в конце 80-х годов, и было приято решение проводить кардинальные реформы по улучшению качества жизни населения в целом, а применение практик партисипаторного бюджетирования являлось новым средством их внедрения, собственно, в 1989-2004 годах эта практика в достаточной мере закрепилась [2].

Несмотря на все трудности, первое применение данной практики специалисты оценили как достаточно успешное, что, впоследствии, привело к её распространению сначала по бразильским штатам, затем по ибероамериканским странам, а в 1996 году на международной конференции в Стамбуле данная методика была признана одной из лучших по решению социальных 
проблем, что в дальнейшем позволило партисипаторному бюджетированию достаточно динамично оказывать своё воздействие на развитые и развивающиеся страны по всему миру (рисунок 1).

Развитие практики партисипаторного бюджетирования представляет собой пять стадий:

На первой стадии проводилось применение соответствующих практик в Порту-Алегри в 1989 году и Монтевидео в 1997 году, что соответствовало с периодами нахождения у власти 2 правительств Бразилии: первое - с 1989 по 1992 годы, второе - 1993 по 1996 годы, когда около 30 муниципальных образований одновременно включились в данную программу. Особенно сильно на развитие партисипаторного бюджетирования влияла стремительно увеличивающийся уровень бедности населения и динамичная миграция сельского населения в городскую среду. Именно в этот период начинают осуществляться либеральные реформы, что значительно меняет жизненные условия, обеспечивая при этом городское население социально-бытовой инфраструктурой.

Приход к власти нового правительства Бразилии в конце 90-х годах предшествует второй стадии за время которой около 140 муниципальных образований начали осваивать разнообраз- ные практики партисипаторного бюджетирования, существенно отличавшиеся друг от друга.

Распространен данных практик по муниципальным образованиям Европы и Латинской Америки характеризует возникновение третьей стадии в начале XXI столетия. Несмотря на то, что данный механизм появился у оппозиционных партий, тем не менее, практика партисипаторного бюджетирования была признана одной их самых успешных «good governance», и могла быть применена в условиях любого населенного пункта, учитывая его социально-экономические особенности.

Возникновение профессиональных групп в 2007-2008 годах связано с началом четвертой стадии партисипаторного бюджетирования в ибероамериканских и европейских странах, что связано с распространением таких практик как Participatory Budget Initiative, PB Unit, Participatory Budgeting Project и др. Именно в этот период формируются экспертные сообщества, имеющие опыт применения практик партисипаторного бюджетирования. Трансформация данного механизма в более сложные методики осуществляются на пятой стадии, где происходит активное вовлечение населения в решение проблем местного значения. В настоящее время в разных странах применяется свыше

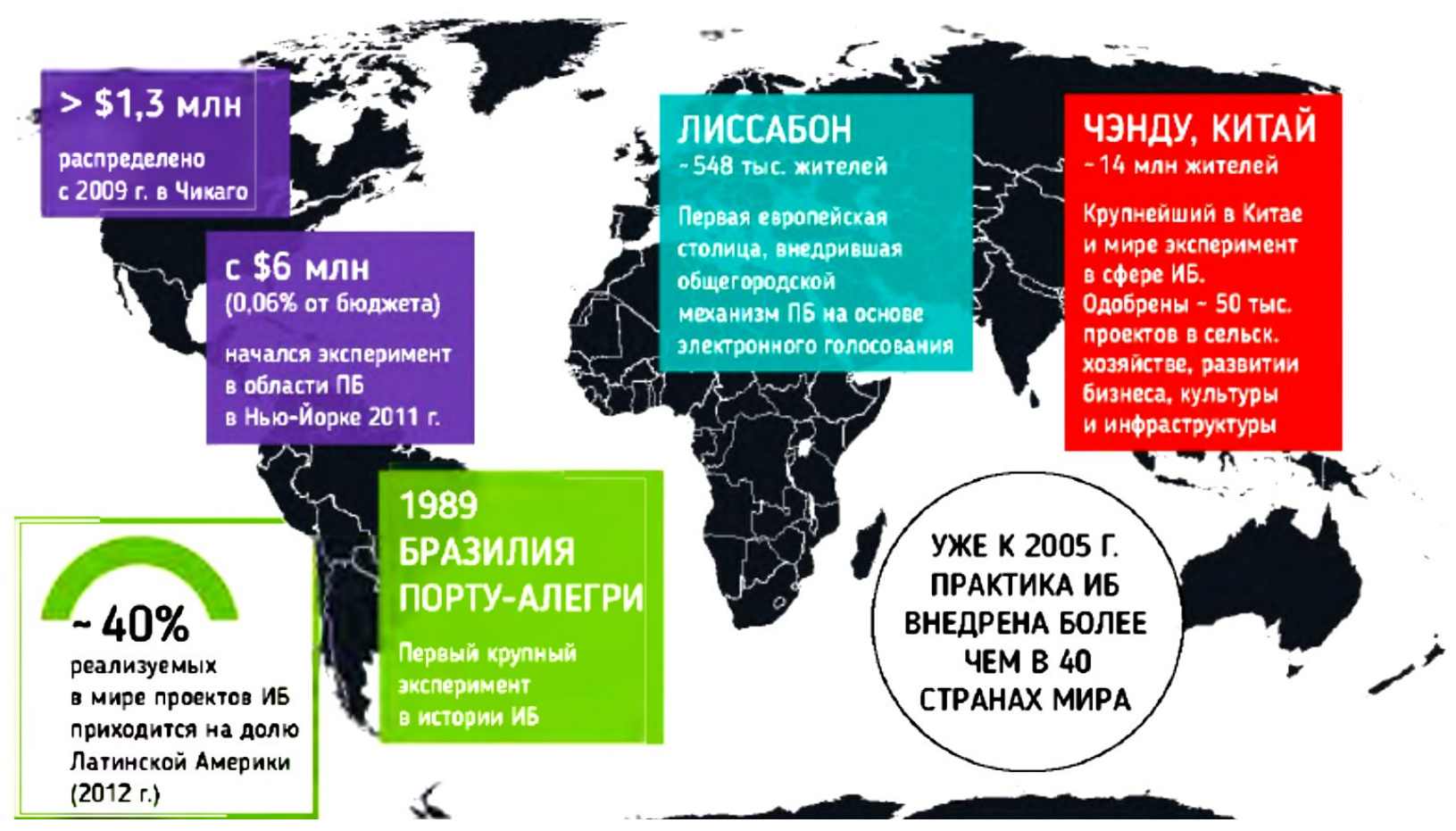

Pис. 1. Зарубежный опыт развития практик инициативного бюджетирования

Источник. Вагин В.В., Тимохина Е.А. 25 Вопросов об инициативном бюджетировании: учебное пособие. Москва. 2017. 46 с. 
2000 практик партисипаторного бюджетирования, но около половины всех инициатив можно отнести к латиноамериканским странам.

Отечественная практика партисипаторного бюджетирования началась совсем недавно, так, например, в 2016 году в 35 регионах России применялось на практике более 8700 инициатив это в 3 раза больше, по сравнению с 2015 годом. Количество зарегистрированных инициатив составило 4237 в 2015 году и 13531 в 2016 году.

Анализ показателей региональных программ инициативного бюджетирования, обнародованных органами власти в 2016 году, дал возможность выделить 15 лучших регионов России в анализируемом периоде на основе определенных требований. Активное участие населения в эффективном расходовании бюджетных ресурсов на местном уровне позволило выйти за рамки планируемых мероприятий.

Учитывая однотипность признаков лучшие 15 регионов внутри разбиты на 3 подгруппы:

1. Многопрограммного инициативного бюджетирования.

2. Монопрограммного инициативного бюджетирования.

3. Новички инициативного бюджетирования.

В первую группу входят субъекты РФ, с многопрограммным инициативным бюджетированием, что обусловлено применением одновременно нескольких методик, финансируемых из бюджетных источников на разных уровнях бюджетной системы. К ним можно отнести следующие регионы России: Республика Башкортостан, Вологодская область, Кировская область, Ульяновская область, Хабаровский край.

Вторую группу инициативного бюджетирования формируют субъекты с применением практик монопрограммного инициативного бюджетирования, в которых реализуется, в течение нескольких лет, одной методики инициативного бюджетирования при отсутствии других вариантов. Это способствует развитию индивидуальных программ развития для каждого региона, учитывающие его специфику. В целом позволяет, определить приоритетные направления развития. К таким регионам следует отнести:

- Иркутскую область - с многолетней практикой применения, реализованной на основе интернет-решений;

- Тверскую область - с применением про- грамм поддержки местных инициатив;

- Тульскую область - с развитием онлайн-технологий;

- Нижегородскую область - с масштабом административного управления;

- Ставропольский край - с направлениями софинансирования проектов;

- Республику Карелия с практикой стимулирования развития муниципальных образований;

- Республику Марий Эл - с масштабом административного управления.

Состав третьей группы обусловлен субъектами РФ, которые только начали применять индивидуальные практики инициативного бюджетирования:

- Санкт-Петербург в котором реализована методика инициативного бюджетирования;

- Ярославская область с новыми финансовыми возможностями решения вопросов местного значения;

- Республика Коми с новым финансовым механизмом [3, с.119-120].

Бюджетное финансирование программ инициативного бюджетирования на региональном уровне осуществляется по программно-целевому методу в рамках федеральных целевых программ, которые утверждаются на соответствующих уровнях бюджетной системы. В настоящее время, приоритетными направлениями государственных программ в рамках инициативного бюджетирования, прежде всего следует выделить:

1. Систему управления финансами.

2. Органы местного самоуправления.

3. Развитие институтов гражданского общества.

4. Предприятия агропромышленного комплекса.

Практика инициативного бюджетирования в отдельных регионах может реализовываться вне рамок государственных программ на основании федеральных, региональных или местных законов с вариантами многопрограммного бюджетного финансирования (табл.).

Оставшиеся за пределами топ-15 20 регионов, подтвердивших реализацию инициативного бюджетирования в 2016 г., развивают практики инициативного бюджетирования на субъектовом и муниципальном уровнях. Среди них есть как участники Соглашения, так и самостоятельно внедряющие механизмы иници- 
Таблица. Инициативное бюджетирование в составе государственных программ субъектов Российской Федерации в 2016 г.

\begin{tabular}{|c|c|}
\hline $\begin{array}{c}\text { Тематнческая направленность } \\
\text { государственных, ведомственных целевых } \\
\text { и муниципальных программ субъектов } \\
\text { РФ, в рамках которых финансируются } \\
\text { проекты инициативного бюджетирования }\end{array}$ & Субъекты РФ \\
\hline $\begin{array}{l}\text { Устойчивое развитие сельских территорий; } \\
\text { развитие сельского хозяйства и } \\
\text { регулирование рынков сельскохозяйственной } \\
\text { продукции, сырья и продовольствия }\end{array}$ & $\begin{array}{l}\text { Алтайский край, Вологодская область, } \\
\text { Липецкая область, Республика Алтай, } \\
\text { Республика Коми, ХМАО - Югра, } \\
\text { Хабаровский край }\end{array}$ \\
\hline $\begin{array}{l}\text { Совершенствование государственного } \\
\text { управления, развитие местного } \\
\text { самоуправления; региональная политика и } \\
\text { развитие территорий. } \\
\text { Развитие институтов гражданского общества, } \\
\text { поддержка социально ориентированных } \\
\text { некоммерческих организаций, устойчивое } \\
\text { общественное развитие, создание условий для } \\
\text { обеспечения общественного согласия, } \\
\text { укрепление национального единства }\end{array}$ & $\begin{array}{l}\text { Архангельская область, Воронежская } \\
\text { область, Кировская область, Костромская } \\
\text { область, Ленинградская область, Санкт- } \\
\text { Петербург, Новгородская область, } \\
\text { Пензенская область (Пенза), Пермский } \\
\text { край, Республика Бурятия, Республика } \\
\text { Карелия, Хабаровский край, Ярославская } \\
\text { область }\end{array}$ \\
\hline \begin{tabular}{llr} 
Управление & государственными \\
общественными & \multicolumn{2}{c}{ финансами, } \\
государственным & долгом, регулирование \\
межбюджетных & отношений, налоговая \\
политика & \\
\end{tabular} & $\begin{array}{l}\text { Владимирская область, Вологодская } \\
\text { область, Кировская область, Республика } \\
\text { Башкортостан, Республика Коми, } \\
\text { Ставропольский край, Тверская область, } \\
\text { Ульяновская область }\end{array}$ \\
\hline $\begin{array}{l}\text { Экономическое развитие, инновационная } \\
\text { экономика, инвестиционная деятельность. } \\
\text { Доступное и комфортное жилье, ЖКХ, } \\
\text { благоустройство, культура, туризм, спорт, } \\
\text { физическая культура, транспорт, дорожное } \\
\text { хозяйство, образование }\end{array}$ & $\begin{array}{l}\text { Иркутская область, Республика Марий Эл, } \\
\text { Республика Коми, Калининградская } \\
\text { область, Краснодарский } \\
\text { (Новороссийск), Москва, Свердловская } \\
\begin{array}{l}\text { область (Новоуральск), Ярославская } \\
\text { область }\end{array} \\
\end{array}$ \\
\hline Непрограммные мероприятия & Нижегородская область, Тульская область \\
\hline
\end{tabular}

Источник. Вагин В.В., Шаповалова Н.А. Состояние инициативного бюджетирования в Российской Федерации: новые тренды и возможности развития. Финансовый журнал / Financial Journal. № 1. 2018. C.113-114.

ативного бюджетирования, кроме того, к этой группе отнесены развивающие смежные практики субъекты РФ. Необходимо отметить самостоятельный опыт регионов: запуск субъектовых программ инициативного бюджетирования в Курской области в 2017 г., не участвующие в Соглашении по развитию инициативного бюджетирования в 2016-2018 гг. [3, с. 120].

Учитывая региональную специфику и используя отечественный и зарубежный опыт партисипаторного бюджетирования население Курской области может получить решение актуальных социально-значимых вопросов применяя данную практику в муниципальных образованиях.

Показателем является доля субъектов Российской Федерации, утвердивших программу (мероприятия) по развитию инициативного бюджетирования в составе государственных программ субъекта Российской Федерации, в общем количестве субъектов Российской Федерации, процентов, а ожидаемый результат - разработка и утверждение субъектами Российской Федерации программ (мероприятий) по развитию инициативного бюджетирования [4].

При решении задач социально-экономического и территориального развития необходимо эффективно осваивать бюджетные средства в процессе исполнения регионального бюджета, а также осуществлять контрольные мероприятий и постоянно проводить анализ имеющихся бюджетных ресурсов региона [1, с. 58].

Оценка успешности реализации практик и программ инициативного бюджетирования 
основана на сочетании оценок результатов программы и её эффектов. Первые позволяют намечать нормы и отслеживать динамику реализации программы, её собственный рост и развитие.
Вторые служат целями оценки долгосрочного и масштабного вклада программы в социально-экономическую систему региона[5].

\section{Библиографический список}

1. Белостоцкий А. А. Исполнение регионального бюджета по доходам за 2016 год / II Международная научная конференция студентов и молодых ученых «Молодежь и системная модернизация страны» сб. науч. стат. Курск. 2018. 420с.

2. Вагин B.В., Тимохина Е.А. 25 Вопросов об инициативном бюджетировании: учебное пособие. Москва. 2017. 46c.

3. Вагин В.В., Шаповалова Н.А. Состояние инициативного бюджетирования в Российской Федерации: новые тренды и возможности развития //Финансовый журнал / Financial Journal. № 1. 2018. C. 110-122.

4. Лавров А.М. Практика инициативного бюджетирования в субъектах РФ Круглый стол «Инициативное бюджетирование как важный фактор социально-экономического развития субъектов РФ» 5 декабря 2017 г. Официальный сайт Совета Федерации Федерального собрания РФ: официальный сайт URL: http://www. council.gov.ru/media/files/1h99uVOK05 ia7rkZfgAAPf5A6vATScwA.pdf(дата обращения: 12.11.2018).

5. Программа развития инициативного бюджетирования в Российской Федерации. Протокол заседания Правительственной комиссии по координации деятельности открытого правительства от 20 декабря 2017 г. № 6 (приложение № 3). Москва, 2017 г. Официальный сайт Министерства Российской Федерации: официальный сайт. URL: http:// minfin.ru/ (дата обращения: 27.11.2018). 